\title{
Diversity of virulence of Pyricularia oryzae isolates obtained from a single lesion of wheat
}

\author{
Mateus da Silveira Lorenset ${ }^{1}$, Raissa Canabarro ${ }^{1}$, Mireli Bergmann ${ }^{2}$, Maria Fernanda Antunes da Cruz ${ }^{3}$ (D)
}

10.1590/0034-737X202168020004

\begin{abstract}
The objective of this study was to evaluate the virulence of Pyricularia oryzae isolates obtained from a single leaf blast lesion on wheat. The wheat cultivars (BRS Louro, BR 18, BRS Tarumã, BRS Parrudo, BRS 208) at the four-leaf stage were inoculated with a suspension of 100.000 conidia/mL. A significant difference was observed in the severity in the cultivars. Among the evaluated isolates, it was possible to observe differences in the susceptibility of the cultivars. Severity data ranged from 3.3 to $99.54 \%$ among treatments. Isolates 1 and 2 were the most aggressive for all cultivars tested. The greatest disease severity occurred in the interactions BRS $208 \mathrm{x}$ isolate 1 (99.54\%), BRS Louro $\mathrm{x}$ isolate 2 (99.34\%), and BRS $208 \mathrm{x}$ isolate 2 (99.09\%). The lowest disease severity was observed in BRS Tarumã (68\%) and BR $18(75 \%)$ cultivars for the isolates 1 and 2 , respectively. Isolate 3 presented medium aggressiveness in which the cultivars presented between 44 to $58 \%$ of wheat blast severity. The isolate 4 was the least aggressive for all cultivars with severity indexes ranging from 3 to $12 \%$. These data indicate the existence of virulence diversity in $P$. oryzae isolates obtained from a single lesion.
\end{abstract}

Keywords: genetic resistance; genetic variability; monosporic isolates; wheat blast.

\section{INTRODUCTION}

Wheat blast disease was first discovered in the state of Paraná, Brazil in 1985 (Igarashi et al., 1986). Since then, the disease has been recorded in different Brazilian states and in South America (Maciel et al., 2014). Known as one of the most important plant pathogenic fungi, Pyricularia oryzae has an unusual capacity of rapidly changing its genetic makeup resulting in new pathogenic variants (Dean et al., 2012). In February 2016, wheat blast was observed in eight districts in Bangladesh, and caused losses in the yield, reaching up to $100 \%$. The phylogenetic and population genomic analyses revealed that the wheat blast outbreak in Bangladesh was most likely caused by a wheatinfecting South American lineage of the blast fungus Magnaporthe oryzae (Islam et al., 2016). It had been already pointed out that, under field conditions, most of the genetic variations in $P$. oryzae were induced by mutation and parasexual recombination (Noguchi et al., 2006). Consequently, the fungus exhibits a high degree of genetic variability; however, the main question of how the genetic makeup of the fungus changes so rapidly remains unanswered. Therefore, the objective of this study was to evaluate the virulence of $P$. oryzae isolates obtained from a single lesion when inoculated on five different wheat cultivars. The hypothesis of this work is as follows: if the monosporic isolates of P. oryzae from the same lesion have genetic diversity, different levels of severity will be observed in the group of plants tested.

\section{MATERIAL AND METHODS}

For the experiment, the wheat cultivars BR 18 (resistant), BRS 208 (susceptible), and BRS Louro, BRS Tarumã, BRS Parrudo (no information about blast resistance) were selected according to the Technical

Submitted on March $26^{\text {th }}, 2020$ and accepted on November $2^{\text {nd }}, 2020$.

'Universidade Federal do Pampa, Campus Itaqui, Itaqui, Rio Grande do Sul, Brazil. mateussilveiralorenset@gmail.com; raissacanabarro@gmail.com; mirelibergman@gmail.com; mariacruz@unipampa.edu.br

*Corresponding author: mariacruz@unipampa.edu.br 
Recommendations for Wheat and Triticale Crop 2018 (RCBPTT, 2018). Wheat seeds were surface-sterilized in $10 \% \mathrm{NaOCl}$ for $2 \mathrm{~min}$, washed in sterilized water for $3 \mathrm{~min}$, and sown in $500-\mathrm{mL}$ plastic pots, filled with substrate composed of biosynthesized Pinnus bark, vermiculite, charcoal mill, water and phenolic foam. The plants were fertilized with modified nutrient solution of Hoagland \& Arnon (1950) on a week basis. Initially, to obtain the isolates, susceptible cultivar BRS 208 was inoculated with the monosporic isolate of $P$. oryzae UFV-DFP-01 (monosporic isolate obtained from the rachis of cultivar BR18, Viçosa, MG, BR). After inoculation, samples of young leaves of cultivar BRS 208 were selected, and kept in a humid chamber for 24 hours. A typical blast lesion was selected and monosporic isolates were obtained from this sample. In the present experiment, four of these isolates were used.

The isolates were preserved in filter paper strips on silica gel at $4^{\circ} \mathrm{C}$. Fifteen days before inoculation, pieces of these strips were plated in Petri dishes containing oatagar medium. When the colony of the fungus reached 3 $\mathrm{cm}$ in diameter, it was peeled into new Petri dishes containing oat-agar, and maintained for twelve days in a growth chamber $\left(25^{\circ} \mathrm{C}\right.$ and photoperiod of 12 hours light) until inoculation. Plants in stage 13 (Zadoks et al., 1974) with four leaves fully expanded were inoculated with a conidial suspension of P. oryzae at 100.000 conidia / mL. The inoculum was sprayed on the adaxial and abaxial leaves surface until runoff using a manual atomizer. After inoculation, the plants were submitted to an initial 24-h dark period. After that, the photoperiod was adjusted to 12-h light. The plants were maintained in a growth chamber at a temperature $25 \pm 2{ }^{\circ} \mathrm{C}$ and the relative humidity was $90 \pm 5 \%$. Five days after inoculation, the severity of the wheat blast was evaluated in the third leaf from the base to the top of each plant using the diagrammatic scale with severity values ranging from 0 to $100 \%$ (IRRI, 1996).

The experiment consisted of $5 \times 4$ factorial with five cultivars and four isolates, arranged in a completely randomized design, with five replications. Each repetition consisted of six plants in a plastic pot. The severity data were submitted to analysis of variance (ANOVA) and the means of the treatments were compared by Tukey's test $(\mathrm{P} \leq 0.05)$ using the SISVAR software (Ferreira, 2008).

\section{RESULTS AND DISCUSSION}

It was observed in this study a significant difference ( $p=0.001)$ in the cultivar and isolate factors and also in the interaction between the factors. According to the data shown in Table 1, the severity ranged from 3.3 to $99.54 \%$ among treatments. Isolate 4 was the least aggressive for the tested cultivars, with severity ranging from 3.3 to $11.9 \%$. For this isolate, no diference was found in blast severity among cultivars. The mean values of the severity for isolate 3 ranged from 43.86 to $58.18 \%$ among cultivars. Isolate 3 presented medium aggressiveness, and no significant difference was observed in blast severity among cultivars. The isolates 1 and 2 were the most aggressive for the cultivars. The mean values of severity for isolate 1 ranged from 67.72 to $99.54 \%$. The lowest severity was verified in the cultivar Tarumã, which did not differ significantly from the cultivar BR 18 (88.66\%). The severity averages for isolate 2 ranged from 74.77 to $99.34 \%$. The cultivar BR18 presented the lowest disease severity, to this isolate, differing statistically from the other cultivars. In this study, all cultivars were considered susceptible to isolates 1,2 and 3, and resistant to isolate 4. In a preliminary work carried out with the parental isolate (UFV-DFP-01), the cultivars BRS Louro, BR 18 and BRS 208 showed the following severity levels, respectively: $85 \%, 60 \%$ and $35 \%$ (unpublished data).

Although sexual reproduction may confer a greater genetic variability among microorganisms, the importance of asexual reproduction for this pathogen should not be disregarded. In the present experiment, the isolate from a single lesion allowed the identification of different levels of severity (low, medium and high) in a reduced number of cultivars (five). That is, even in a short time and in a reduced leaf area, the pathogen may be undergoing changes in its genome, which result in different levels of blast severity in wheat cultivars. These changes may contribute to the production of $P$. oryzae genotypes with higher plasticity, aggressiveness, and greater resistance to environmental conditions and fungicides.

To explain the high genetic variability presented by $P$. oryzae, studies have pointed out both for the importance of asexual and sexual reproduction, even though the latter has not been evidenced in field conditions. Pagliaccia et al. (2018), when analyzing the genetic structure of $P$. oryzae from isolates collected from the initial identification of the disease in 1990 to more recently sampled isolates, evidenced a significant increase in genotypic diversity over the time, but without evidence of sexual reproduction. However, the high genetic variability in P. oryzae in wheat, which contributes to the lack of blast durability of resistance in wheat cultivars, was related to the sexual reproduction capacity between wheat isolates and weeds such as Brachiaria plantaginea and Setaria geniculata (Bruno \& Urashima, 2001). According to Maciel et al. (2014), the pathogen performs both sexual and asexual reproduction in the field. New genotypes of pathogens produced by sexual recombination may be favored by selection and increased frequency via asexual reproduction within each wheat growing area, spreading like clones over short distances through conidia. Different from those presented by these authors, the present work 
indicates that even in a small and unique lesion, the fungus presents genetic variability. When the severity levels of three of these cultivars are compared with the response to parental isolate (UFV-DFP-01), it is observed that the tendency of susceptibility of the cultivars is maintained, with alteration in the severity levels for 3 of the 4 isolates. Probably, these facts may contribute to the understanding of the variation in the results presented in different studies evaluating the fungus aggressiveness on different cultivars since the identification of the disease in Brazil (Urashima et al., 2004; Arruda et al., 2005; Prestes et al., 2007; Cruz et al., 2009, 2010; Maciel et al., 2014).

The cultivar BR 18, for example, is considered as resistant or partially resistant to wheat blast in the heading stage (RCBPTT, 2018; Prestes et al., 2007; Rios et al., 2016). However, for leaf resistance, differentiated responses were observed in the literature (Urashima et al., 2004; Cruz et al., 2009). In the present work, the cultivar BR 18 was considered susceptible to 3 of the 4 isolates tested, with severity ranging from 55 to $88.86 \%$. Similar results were observed by Cruz et al. (2009), in a study carried out with 18 monosporic isolates of $P$. oryzae obtained from different geographical regions in Brazil. Using a greater number of isolates (72) obtained from the Mato Grosso do Sul and Paraná States, Urashima et al. (2004) verified that cultivar BR18 exhibited a broad resistance spectrum in relation to the rest of the tested cultivars, showing resistance to more than $50 \%$ of the isolates of the both States. Cruz et al. $(2009,2010)$ observed the susceptibility of BRS 208 and BRS Louro cultivars for 17 monosporic isolates of $P$. oryzae, similar to that observed in this study, where the highest severity indices were observed in these cultivars. The BRS Tarumã is a cultivar with double purpose (forage and grains), considered moderately susceptible to leaf spots (Fontanelli et al., 2016). The BRS Parrudo is a cultivar characterized as moderately resistant to leaf spots (Pyrenophora triticirepentis and Bipolaris sorokiniana) (Scheeren et al., 2014). Information on the reaction of BRS Tarumã and BRS Parrudo cultivars to wheat blast has not been found in the literature.
According to this study in relation to the response of the tested cultivars, the fungus simply undergoes periodic changes, even within a single lesion, without the pressure of a selection factor. Ou \& Ayad (1968), observed that from monoconidial cultures isolated from one typical leaf rice blast lesion, and respective monoconidial subcultures of the original isolates allowed the identification of different pathogenic races of $P$. oryzae. For these authors, the cells of both mycelium and conidia are multinucleated and anastomosis as well as nucleus migration could contribute to the production of heterodiploid forms of the pathogen. This would explain the genetic variability of the $P$. oryzae in rice, and the different pathogenicity results found in the set of the differential varieties. Pathogenic variability among monoconidial isolates of Colletotrichum graminicola from single lesions on sorghum and from monoconodial cultures was observed by Casela \& Fredriksen (1994). From each lesion, a total of 20 monoconidial isolates were obtained, followed by the isolation of 20 monoconidial sub-cultures from one isolate of each set of 20 plus an additional generation of 20 monoconidial sub-subcultures from one isolate of each sub-set. Fifteen isolates per lesion were selected, and inoculated onto plants of five sorghum cultivars. The authors confirm the occurrence of pathogenic instability in monoconidial cultures of C.graminicola derived from single lesions and from monoconidial cultures. Despite the possibility that some variability within the single lesion results from infection of different genotypes, these data were helpful in explaining part of the aggressiveness observed in C.graminicola natural populations, as changes in the cultivar host-specificity (Casela \& Fredriksen, 1994). In addition, variation in the virulence and aggressiveness was reported by Scharen \& Krupinsky (1970) in a study with single conidia from Stagonospora nodorum onto wheat.

The molecular analysis of the conidia onto single lesion or monoconidial culture is useful for the genetic characterization of pathogen populations (Linde et al., 2002; Maciel et al., 2014). The spatial distribution of 15

Table 1: Severity of wheat cultivars submitted to inoculation with four monosporic isolates of Pyricularia oryzae obtained from a single BRS 208 blast lesion

\begin{tabular}{llllr}
\hline \multirow{2}{*}{ Cultivar/Severity } & \multicolumn{4}{c}{ Isolates } \\
\cline { 2 - 5 } & \multicolumn{1}{c}{$\mathbf{1}$} & $\mathbf{2}$ & $\mathbf{3}$ & $\mathbf{4}$ \\
\hline BRS Louro & $94.31 \mathrm{C}^{1} \mathrm{c}^{2}$ & $99.34 \mathrm{Bc}$ & $58.18 \mathrm{ABCb}$ & $3.3 \mathrm{Aa}$ \\
BR18 & $88.86 \mathrm{BCcd}$ & $74.77 \mathrm{Ac}$ & $55 \mathrm{ABb}$ & $4.4 \mathrm{Aa}$ \\
BRS Tarumã & $67.72 \mathrm{ABb}$ & $95.9 \mathrm{Bc}$ & $61.36 \mathrm{ABCb}$ & $4.8 \mathrm{Aa}$ \\
BRS Parrudo & $96.36 \mathrm{Cc}$ & $95 \mathrm{Bc}$ & $43.86 \mathrm{Ab}$ & $6.8 \mathrm{Aa}$ \\
BRS 208 & $99.54 \mathrm{Cc}$ & $99.09 \mathrm{Bc}$ & $56.81 \mathrm{ABCb}$ & $11.9 \mathrm{Aa}$ \\
\hline
\end{tabular}

1.2Means followed by the same letter, lowercase in the row and upper case in the column, did not differ statistically by the Tukey's test at the $5 \%$ probability. $\mathrm{CV}=28.62 \%$. 
Mycosphaerella graminicola genotypes found among 158 isolates sampled from five individual lesions was used to determine across a hierarchy of spatial scales using molecular markers. At the smallest spatial scale, each lesion had two to six different genotypes including both mating types in four of the five lesions, but in most cases, a lesion was composed of one or two genotypes that occupied the majority of the lesion, with other rare genotypes interspersed among the common genotypes. Low population differentiation was indicated among populations, suggesting a corresponding high degree of gene flow among these populations. At the largest spatial scale, populations from Switzerland, Israel, Oregon, and Texas were compared. Population differentiation among these populations was low, and genetic identity between populations was high. The hierarchical gene diversity analysis included 1,098 isolates from seven field populations. According Linde et al. (2002), the high levels of gene flow in $M$. graminicola populations on a regional level indicates a significant potential risk for the regional spread of mutant alleles that enable fungicide resistance or the breakdown of resistance genes. Maciel et al. (2014) used 11 microsatellite loci to elucidate the population structure of the wheat blast pathogen in wheat fields in central-western, southeastern, and southern Brazil. However, no subdivision was found among the wheatinfecting populations, consistent with high levels of gene flow across a large spatial scale.

The diversity of virulence and aggressiveness observed in this study and in other works with $P$. oryzae where the evaluated cultivars showed resistance to a restrict number of the patotypes of the pathogen (Urashima et al., 2004; Cruz et al., 2010; Maciel et al., 2014) may be related to the information presented by Peng et al. (2019). The authors observed in the genome of $P$. oryzae strains, seven cromossomes and minicromossomes with highly repetitive and enriched transposons most frequently at the core chromosome ends. Transposons in mini-chromosomes lack the characteristic signature for inactivation by repeat-induced point (RIP) mutation genome defenses. Thus, minichromosomes and core-chromosome ends are coupled as a mobile, fast-evolving effector compartment in the wheat pathogen genome, which may explain the great flexibility of the fungus in adapting to different hosts (Peng et al., 2019). Wicaksono et al. (2017), analyzing the $P$. oryzae genetic diversity through the Repeating Element-based Polymerase Chain Reaction (rep-PCR), collected several samples of the fungus in different regions of Indonesia and observed that, although collected from very close regions, different fungus samples do not always own high genetic similarity. These results show the high capacity of the fungus to make fast and random mutates, designating high genetic diversity. Further studies for the genetic characterization of $P$. oryzae isolates may contribute to the identification of the most frequent mutations in this genome and to the development of more efficient strategies to reduce the damage caused by blast epidemics.

\section{CONCLUSION}

The results of the present work indicate the existence of virulence diversity among P.oryzae isolates obtained from a single lesion on leaves of wheat. Thus, further studies with a greater number of isolates and cultivars and using molecular tools may contribute to the understanding of the genetic diversity of the P. oryzae population.

\section{ACKNOWLEDGEMENTS, FINANCIAL SUPPORT AND FULL DISCLOSURE}

The authors thanks the Fundação de Amparo à Pesquisa do Estado do Rio Grande do Sul (FAPERGS), for granting the scholarship to the first and third authors, and to Conselho Nacional de Desenvolvimento Científico e Tecnológico (CNPq) for granting the scholarships to the second author. There is no conflict of interest in the conduct and publication of the work.

\section{REFERENCES}

Arruda MA, Bueno CRNC, Zamprogno KC, Lavorenti NA \& Urashima AS (2005) Reação do trigo a Magnaporthe grisea nos diferentes estádios de desenvolvimento. Fitopatologia Brasileira, 30:121-126.

Bruno AC \& Urashima AS (2001) Inter-relação sexual de Magnaporthe grisea do trigo e de outros hospedeiros. Fitopatologia Brasileira, 26:21-26.

Casela CR \& Frederiksen RA (1994) Pathogenic varibility in monoconidial isolates of the sorghum anthraconose fungus Colletotrichum graminicola from a single lesion and from monoconidial cultures. Fitopatologia Brasileira, 19:149-153.

Cruz MFA, Prestes AM, Maciel JLN \& Scheeren PL (2010) Resistência parcial à brusone de genótipos de trigo comum e sintético nos estádios de planta jovem e de planta adulta. Tropical Plant Pathology, 35:024-031.

Cruz MFA, Maciel JLN, Prestes AM, Bombonatto EAS, Pereira JF \& Consoli L (2009) Caracterização genética e fenotípica de isolados de Pyricularia grisea do trigo. Tropical Plant Pathology, 34:393- 401 .

Dean R, Van Kan JAL, Pretorius ZA, Kosack KE, Pietro A, Spanu PD, Rudd JJ, Dickman M, Kahmann R, Ellis J \& Foster GD (2012) The Top 10 Fungal Pathogens in Molecular Plant Pathology. Molecular Plant Pathology, 13:414-430.

Ferreira DF (2008) SISVAR: um programa para análises e ensino de estatística. Revista Symposium, 6:36-41.

Fontanelli RS, Santos HP \& Nascimento Júnior A (2016) BRS Tarumã. Passo Fundo, Embrapa Trigo. 2p.

Hoagland R \& Arnon I (1950) The water culture method for growing plants without soil. Circular of the California Agricultural Experiment Station, 347:1-32. 
Igarashi S, Utiamada CM, Igarashi LC, Kazuma AH \& Lopes RS (1986) Pyricularia em trigo. 1. Ocorrência de Pyricularia sp. No estado do Paraná. Fitopatologia Brasileira, 11:351-352.

International Rice Research Institute (1996) Standard Evaluation System for Rice, $4^{\text {th }}$ ed. Manila, Rice Knowledge Bank. 52p.

Islam MT, Croll D, Gladieux P, Soanes DM, Persoons A, Bhattacharjee P, Hossain MS, Gupta DR, Rahman MM, Mahboob MG, Cook N, Salam MU, Surovy MZ, Sancho VB, Maciel JLN, Nhani Júnior A, Castroagudín VL, de Assis Reges JT, Ceresini PC, Ravel S, Kellner R, Fournier E, Tharreau D, Lebrun MH, McDonald BA, Stitt T, Swan D, Talbot NJ, Saunders DGO, Win J \& Kamoun S (2016) Emergence of wheat blast in Bangladesh was caused by a South American lineage of Magnaporthe oryzae. BMC Biology, 14:84.

Linde CC, Zhan J \& McDonald BA (2002) Population structure of Mycosphaerella graminicola: From lesions to continents. Phytopathology, 92:946-955.

Maciel JLN, Ceresini PC, Castroagudin VL, Zala M, Kema GHJ \& McDonald BA (2014) Population structure and pathotype diversity of the wheat blast pathogen Magnaporthe oryzae 25 years after its emergence in Brazil. Phytopathology, 104:95107

Noguchi MT, Yasuda N \& Fujita Y (2006) Evidence of Genetic Exchange by Parasexual Recombination and Genetic Analysis of Pathogenecity and Mating Type of Parasexual Recombinants in Rice Blast Fungus Magnaporthe oryzae. Phytopathology, 96:746-750

Ou SH \& Ayad MR (1968) Pathogenic Races of Pyricularia oryzae originating from single lesions and monoconidial cultures. Phytopathology, 58:179-182.

Pagliaccia D, Urak RZ, Wong F, Douhan LI, Greer CG, Vidalakis G \& Douhan GW (2018) Genetic Structure of the Rice Blast Pathogen (Magnaporthe oryzae) over a Decade in North Central California Rice Fields. Microbial Ecology, 75:310-317.
Peng Z, Oliveira-Garcia E, Lin G, Hu Y, Dalby M, Migeon P, Tang H, Farman M, Cook D, White FF, Valent B \& Liu S (2019) Effector Gene Reshuffling Involves Dispensable Minichromosomes in the Wheat Blast Fungus. PLoS Genet, 15:e1008272.

Prestes AM, Arendt PF, Fernandes JMC \& Scheeren PL (2007) Resistance to Magnaporthe Grisea Among Brazilian Wheat Genotypes. In: Buck HT, Nisi JE \& Salomón N. (Ed.) Wheat Production in Stressed Environments. Dordrecht, Developments in Plant Breeding/Springer. p.119-123.

Reunião da Comissão Brasileira de Pesquisa de Trigo e TriticaleRCBPTT (2018) Informações Técnicas para trigo e triticalesafra 2018. Cascavel, Coodetec. 258p.

Rios JA, Rios VS, Paul PA, Souza MA, Araujo L \& Rodrigues FA (2016) Fungicide and cultivar effects on the development and temporal progress of wheat blast under field conditions. Crop Protection, 89:152-160.

Scharen AL \& Krupinsky JM (1970) Cultural and inoculation studies of Septoria nodorum, cause of glume blotch of wheat. Phytopathology, 60:1480-1485.

Scheeren PL, Caierão E, Castro MSS, Pires JL, Wiethölter S \& Faé GS (2014) BRS Parrudo. Passo Fundo, Embrapa Trigo. 2p.

Urashima AS, Lavorent NA, Goulart ACP \& Mehta YR (2004) Resistance spectra of wheat cultivars and virulence diversity of Magnaporthe grisea isolates in Brazil. Fitopatologia Brasileira, 29:511-518.

Wicaksono D, Wibowo A \& Widiastuti A (2017) Genetic Diversity of Pyricularia oryzae, the Causal Agent of Rice Blast Disease, Based on Repetitive Element-Based Polymerase Chain Reaction. In: Isnansetyo A \& Nuringtyas T (Ed.) Proceeding of the 1st International Conference on Tropical Agriculture. Cham, Springer. p.41-47.

Zadoks JC, Chang TT \& Konzak CF (1974) A decimal code for the growth stages of cereals. Weed Research, 14:415-421. 